\title{
Low Serum Levels of Pepsinogen and Gastrin 17 Are Predictive of Extensive Gastric Atrophy with High-Risk of Early Gastric Cancer
}

\author{
Ryousuke Kikuchi, ${ }^{1}$ Yasuhiko Abe, ${ }^{1}$ Katsunori Iijima, ${ }^{1}$ Tomoyuki Koike, ${ }^{1}$ \\ Nobuyuki Ara, ${ }^{1}$ Kaname Uno, ${ }^{1}$ Kiyotaka Asanuma, ${ }^{1}$ Naoki Asano, ${ }^{1}$ Akira Imatani ${ }^{1}$ \\ and Tooru Shimosegawa ${ }^{1}$
}

${ }^{1}$ Division of Gastroenterology, Tohoku University Graduate School of Medicine, Sendai, Japan

\begin{abstract}
Atrophic gastritis (AG) is a well-recognized high-risk condition for developing gastric cancer (GC). Gastrin 17 (G17), a hormone secreted from antral G cells, regulates gastric acid secretion, and its serum level is a possible indicator of antral atrophy. Serum pepsinogen is well established as the indicator of AG involving the corpus. Here we investigated whether serum PG and $G 17$ levels would be useful for determining the topographic pattern of $A G$ and estimating the risk of GC. Enrolled were 122 Japanese patients with early GC (114 well- to moderate-differentiated cancers and 8 poorly-differentiated cancers). In addition, 178 subjects without GC were recruited as control from those undergoing endoscopic examination (non-GC group). All subjects were histologically assigned to the following four groups: non-AG, antrum-predominant $A G$, corpus-predominant $A G$, and multifocal $A G$, affecting the antrum and corpus. Serum concentrations of pepsinogen and G17 were determined using ELISA. Multifocal AG was more frequent in the GC group than in the adjusted non-GC group, and had the highest risk of GC (OR 25.1). Serum G17 was significantly decreased with the exacerbation of antral atrophy in the coexistence of corpus atrophy. Serum biomarker profiles showed that the low levels of pepsinogen and G17 could discriminate between multifocal AG and other types of AG, but not with pepsinogen level alone. Serologically defined multifocal AG had the highest cancer risk among other serologically defined AG groups (OR 26.9). In conclusion, the low serum levels of pepsinogen and G17 are predictive of extensive gastric atrophy with high-risk of early GC.
\end{abstract}

Keywords: serum gastrin 17; serum pepsionogen; atrophic gastritis; gastric cancer; antral atrophy

Tohoku J. Exp. Med., 2011, 223 (1), 35-44. (C) 2011 Tohoku University Medical Press

Atrophic gastritis is a well-recognized high-risk condition for developing gastric cancer, especially for intestinaltype cancer (Siurala et al. 1966; Svendsen et al. 1986; Correa et al. 1990), and the risk varies depending on the severity or topography of the atrophic change (Cassaro et al. 2000; Uemura et al. 2001). Although corpus atrophy and its accompanying hypochlorhydria is known to be a primarily important risk factor for gastric cancer, histological analyses suggest that co-existing antral atrophy could represent additional substantial risk for gastric cancer in individuals with corpus atrophy (Sipponen and Stolte 1997; Rugge et al. 2007). Thus, currently, extensive gastric atrophy spreading in both gastric corpus and antrum, referred to as multifocal atrophic gastritis (MAG), is widely recognized to be the most risky form of gastric atrophy for developing gastric cancer (Faraji and Frank 2002).

Upper gastrointestinal endoscopy with sampling of multiple biopsies from the gastric antrum and corpus is required to determine the topographical distribution and severity of gastric atrophy. However, its use for screening for the prevention of gastric cancer is generally limited because of its invasiveness and cost. Therefore, a number of studies have attempted to seek ideal serological markers for gastric atrophy (di Mario and Cavallaro 2008). Serum pepsinogen (PG) is at present the most intensively studied biomarker (Kitahara et al. 1999; Varis et al. 2000; Broutet et al. 2003; Miki et al. 2003). PG I is secreted exclusively by the fundic glands (Samloff 1971), and PG II is secreted by the fundic glands, pyloric glands, and the proximal duodenal mucosa (Samloff and Liebman 1973). It has been shown that the decreases in serum PG I and PG I/II ratio correlate well with the severity of corpus atrophic gastritis and gastric acid hyposecretion (Miki et al. 1987; Borch et al. 1989), indicating that serum PG is a useful biomarker reflecting the morphological and functional status of the gastric corpus mucosa. Therefore, measurement of serum

Received September 13, 2010; revision accepted for publication December 11, 2010. doi: 10.1620/tjem.223.35

Correspondence; Yasuhiko Abe, Division of Gastroenterology, Tohoku University Graduate School of Medicine, 1-1 Seiryo-machi, Aoba-ku, Sendai, Miyagi 980-8574, Japan.

e-mail; y_abe@mui.biglobe.ne.jp 
PG has been a promising approach to estimate the risk of gastric cancer. Recent prospective cohort studies have proven that the measurement of serum PG can provide an appropriate estimation of the gastirc cancer risk (Watabe et al. 2005; Oishi et al. 2006; Yanaoka et al. 2008). Theoretically, however, due to the PG produced by fundic glands, the serum PG test is unable to evaluate antral atrophy and its related cancer risk.

On the other hand, it has been known that the serum level of gastrin decreases with worsening of antral atrophy (Stockbrugger et al. 1977), but, it has not been utilized to evaluate antral atrophy mainly because of a feedback regulation by intragastric acidity or aggregates of several gastrin fractions derived from gastric antrum and other gastrointestinal tract (Sipponen et al. 1990). Recent studies have reported that gastrin 17 (G17) was exclusively secreted from antral G cells, and its serum level may reflect the severity of antral atrophy more accurately compared with serum total gastrin (Sipponen et al. 2002a, 2002b; Väänänen et al. 2003; Germaná et al. 2005). Consequently, the determination of G17 in combination with serum PG can yield a topographic assessment of atrophic gastritis (antrum- or corpuspredominant atrophic gastritis or multifocal atrophic gastritis), potentially serving as a serological risk assessment of gastric cancer. Some previous reports have used an increased level of serum G17 for improving the accuracy for serological detection of corpus atrophic gastritis or estimating the risk for gastric cancer (Shiotani et al. 2005, Rollan et al. 2006, Cao et al. 2007), but no studies have evaluated the topographic pattern of atrophic gastritis and its related cancer risk by using an increased and/or decreased level of serum G17 in combination with serum PG value.

The aim of this case-control study was first to assess the cancer risk of atrophic gastritis by histological topographic assessment in Japanese subjects, and then to investigate whether serum PG and G17 levels would be useful in determining the topographic pattern of $\mathrm{AG}$ and in estimating the risk of gastric cancer.

\section{Material and Methods}

\section{Subjects}

This study population was composed of two patient groups with and without gastric cancer who visited Tohoku University outpatient clinic from July 2006 to February 2009. One group consisted of 122 patients (90 men) with early gastric cancer with a mean age of 68.2 years (range 41-87) (GC group). The other consisted of 178 patients (97 men) without gastric cancer with a mean age of 56.2 years (range 22-82) (non-GC group). In the GC group, 79 patients had a history of complete endoscopic mucosal resection with a lag time of 4 years or less between the enrollment into this study and the endoscopic treatment, and 43 patients were scheduled for endoscopic or surgical treatment. All of the cancers were diagnosed as being confined to the mucosal or submucosal layer by histopathological evaluation of the resected samples. Their histopathological types consisted of 114 well- to moderately-differentiated and 8 undifferentiated (poorly-differentiated) adenocarcinomas.
The majority of the non-GC group subjects had been recruited from our previous study to validate the usefulness of measuring serum G17 in combination with PG and anti-Helicobacter pylori $(H$. pylori) antibody (the European Gastropanel examination) for the serological diagnosis of atrophic gastritis in Japan (Iijima et al. 2009). The reasons for endoscopic examination in the non-GC group were as follows; dyspeptic symptoms in 39 subjects, screening purposes in 71 , annual endoscopic check-up in 42, positive results in mass screening with barium meal examinations in 26. The non-GC group was endoscopically diagnosed as scarred stage of gastric or duodenal ulcer in 16 , superficial gastritis in 17 , chronic atrophic gastritis in 66 , and no abnormality in 79 . Those with active or healed stage of gastric or duodenal ulcer were excluded. Other exclusion criteria were medication with proton pump inhibitor, histamine receptor antagonist, steroid, anticoagulant agent, non-steroidal anti-inflammatory agent, previous eradication therapy of $H$. pylori, previous history of gastroduodenal surgery and chronic renal failure. This study was approved by the Ethics Committee for Human Research at Tohoku University Graduate School of Medicine, Sendai, Japan and informed consent was obtained from each participant.

The histological diagnosis and the topographical classification of the gastric atrophy

Biopsies were taken from four specific sites according to the updated Sydney system (Dixon et al. 1996); two were from the lesser and greater curvatures of the antrum, and the remaining two were from the lesser curvatures of the middle body and the greater curvatures of the upper body. Biopsy specimens were routinely fixed in neutral formalin and processed in paraffin. Tissue sections were stained with Hematoxylin-eosin and modified Giemsa (H. pylori staining) methods. Histological atrophy was defined as a loss of the inherent gastric gland, and the degree was assessed by grading from 0 to 3 based on the visual analogue scale according to the updated Sydney system. Using the mean atrophy score of the respective two biopsies from the antrum and the corpus, the topographical predominance of mucosal atrophy was determined. Mean atrophy score more than 1 was defined to having a AG because one has to be careful in assessing gastric atrophy by histology due to some difficulties in distinguishing the atrophic gland from normal gland, especially in the antrum (Ruiz et al. 2001; Staibano et al. 2002). All subjects were assigned to one of the following four groups:

Non atrophic gastritis (NAG); the atrophy of both the antrum and the corpus was absent or mild irrespective of any metaplastic change, inflammation, or $H$. pylori infection (mean antral atrophy score $\leq 1$, mean corpus atrophy score $\leq 1$ ).

Antrum-predominant atrophic gastritis (APG); the atrophy of the antrum was moderate or severe, while the atrophy of the corpus was absent or mild (mean antral atrophy score $>1$, mean corpus atrophy score $\leq 1)$.

Corpus-predominant atrophic gastritis $(\mathrm{CPG})$; the atrophy of the antrum was absent or mild, while the atrophy of the corpus was moderate or severe (mean antral atrophy score $\leq 1$, mean corpus atrophy score $>1)$.

Atrophic gastritis both in the antrum and the corpus (multifocal atrophic gastritis, MAG); the atrophy of both the antrum and the corpus was moderate or severe (mean antral atrophy score $>1$, mean corpus atrophy score $>1$ ).

The biopsy specimens were interpreted by two experienced pathologists (YA and $\mathrm{AI}$ ) without knowledge of the clinical informa- 
tion or the results of serum biomarkers. Discordant histological diagnose were resolved by joint discussion.

\section{Measurement of serum biomarkers}

Fasting serum samples obtained from all participants were centrifuged immediately at $4{ }^{\circ} \mathrm{C}$ and stored at $-20^{\circ} \mathrm{C}$ until measurement. Serum concentrations of PG I and II were measured using a CLEIA kit (Lumipulse pepsionogen I \& II, Fujirebio Inc, Tokyo, Japan) and H. pylori IgG antibody was measured using an EIA kit (E Plate "Eiken" H. pylori-antibody, Eiken Chemical Co. Ltd., Tokyo, Japan). The measurement of G17 was performed by a specific ELISA kit (Gastropanel, Biohit Plc, Helsinki, Finland).

\section{Determination of $H$. pylori infection}

H. pylori infection status was assessed by histology (Giemsa staining) and serum IgG antibody to $H$. pylori. We considered $H$. pylori negative when both tests were negative, and $H$. pylori positive when at least one of the two tests was positive.

\section{Statistical analysis}

Data with continuous variables were expressed by mean (standard deviation), and compared using Mann-Whitney U test between any two groups (Table 1). Fisher's exact probability test was used for the comparison of the prevalence rate between any two groups (Table 1). In comparison of the topographic pattern of atrophic gastritis between the non-GC group and the GC group, the non-GC patients were adjusted for age by a direct method using the GC patients as the standard population (Table 2). Spearman's rank correlation test was used to detect the significant correlation between serum level of bio- markers and the severity of antral or corpus atrophy (Figs. 1 and 2). Serum biomarker profiles in the four histologically classified groups of atrophic gastritis were compared using Tukey-Kramer test (Fig. 3). According to the histological and serological classification of atrophic gastritis, the risk for gastric cancer was estimated and presented as odds ratio with $95 \%$ confidence interval (95\% C.I.) using univariate and multivariate analysis including age, gender and $H$. pylori infection (Table 3 and 4). Sensitivity, specificity and positive likelihood ratio were calculated to compare the diagnostic performance of the different serological tests using PG or G17 level in detecting gastric cancer (Table 5). A $p$ value less than 0.05 was defined to be statistically significant.

\section{Results}

Basic demographic data, serum biomarker profile, H. pylori prevalence and histological gastric atrophy in $G C$ and non-GC groups

Age, gender, the level of serum biomarkers, H. pylori infection rate, and the degree of histological gastric atrophy in this study population are shown in Table 1. The GC group was significantly older and more male-predominant than the non-GC group. PG I $\leq 70 \mathrm{ng} / \mathrm{ml}$ and $\mathrm{PG} \mathrm{I} / \mathrm{II} \leq 3$ were significantly more prevalent in the GC group than the non-GC group, but $\mathrm{G} 17 \leq 1$ did not differ between the two groups (non-GC $12.4 \%$, GC 15.6\%). H. pylori infection was present in 113 of 182 non-GC subjects $(61.2 \%)$ and in 100 of 122 patients with gastric cancer $(82.0 \%)$, which reached a significant difference. The degree of histological

Table 1. Age, gender, serum biomarker profile, H. pylori prevalence and histological gastric atrophy in this study population.

\begin{tabular}{|c|c|c|c|c|}
\hline & & non-GC group & GC group & $p$ value \\
\hline \multicolumn{2}{|l|}{ number } & 178 & 122 & - \\
\hline \multicolumn{2}{|c|}{ Gender (male/female) } & $97 / 81$ & $90 / 32$ & $p=0.0007 *$ \\
\hline \multicolumn{2}{|c|}{ Age (years old) } & $56.2(14.9)$ & $68.2(9.7)$ & $p<0.0001 * *$ \\
\hline \multirow[t]{2}{*}{ PG I } & $\leq 70 \mathrm{ng} / \mathrm{ml}$ & $148(83.1 \%)$ & $114(93.4 \%)$ & $P=0.0081^{*}$ \\
\hline & $>70 \mathrm{ng} / \mathrm{ml}$ & $30(16.9 \%)$ & $8(6.6 \%)$ & \\
\hline \multirow[t]{2}{*}{ PG I/II ratic } & io $\leq 3$ & $83(46.6 \%)$ & $100(82.0 \%)$ & $P<0.0001^{*}$ \\
\hline & $>3$ & $95(53.4 \%)$ & $22(18.0 \%)$ & \\
\hline \multirow[t]{2}{*}{ G17 } & $<1 \mathrm{pmol} / 1$ & $22(12.4 \%)$ & $19(15.6 \%)$ & n.s. \\
\hline & $>1 \mathrm{pmol} / 1$ & $156(87.6 \%)$ & $103(84.4 \%)$ & \\
\hline \multirow[t]{2}{*}{ H. pylori } & positive & $109(61.2 \%)$ & $100(82.0 \%)$ & $P=0.0001^{*}$ \\
\hline & negative & $69(38.8 \%)$ & $22(18.0 \%)$ & \\
\hline \multicolumn{5}{|c|}{ Histological gastric atrophy } \\
\hline \multicolumn{2}{|c|}{ antrum lc } & $0.6(1.0)$ & $1.9(1.1)$ & $P<0.0001 * *$ \\
\hline \multicolumn{2}{|c|}{ antrum gc } & $0.4(0.7)$ & $1.4(1.1)$ & $P<0.0001 * *$ \\
\hline \multicolumn{2}{|c|}{ corpus lc } & $1.3(1.3)$ & $2.6(0.7)$ & $P<0.0001 * *$ \\
\hline \multicolumn{2}{|c|}{ corpus gc } & $0.5(0.7)$ & $1.5(0.9)$ & $P<0.0001 * *$ \\
\hline
\end{tabular}

Age was represented by mean (standard deviation). Histological gastric atrophy was assessed by grading from 0 to 3 based on the updated Sydney system, and expressed as mean (standard deviation). Non-GC group, non gastric cancer group; GC group, gastric cancer group; PG, pepsinogen; G17, gastrin17; lc, lesser curvature; gc, greater curvature. *Fisher's exact probability test, **Mann-Whitney $U$-test. $P$ value was calculated between the non-GC group and the GC group. 
Table 2. The proportion of the topographic pattern of gastric atrophy in the control group and the gastric cancer group.

\begin{tabular}{ccccc}
\hline & non-GC group (\%) & Adjusted non-GC group (\%)* & GC group (\%) & $p$ value** \\
\hline NAG & $96(53.9 \%)$ & $41.5(34.0 \%)$ & $7(5.7 \%)$ & $P<0.0001$ \\
APG & $6(3.4 \%)$ & $4.1(3.4 \%)$ & $6(4.9 \%)$ & n.s. \\
CPG & $53(29.8 \%)$ & $54.1(44.3 \%)$ & $45(36.9 \%)$ & n.s \\
MAG & $23(12.9 \%)$ & $22.3(18.2 \%)$ & $64(52.5 \%)$ & $P<0.0001$ \\
\hline
\end{tabular}

NAG, histological non-atrophic gastritis; APG, histological antrum-predominant atrophic gastritis; CPG, histological corpus-predominant atrophic gastritis; MAG, histological multifocal atrophic gastritis; non-GC group, non gastric cancer group; GC group, gastric cancer group.

*The control subjects are adjusted for age by a direct method using the gastric cancer patients as the standard population.

**P value was calculated between the adjusted non-GC group and the GC group by Fisher's exact probability test.

A

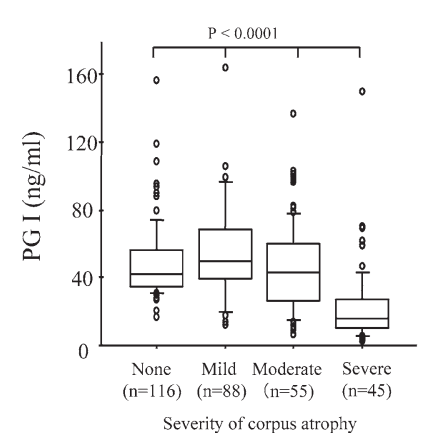

B

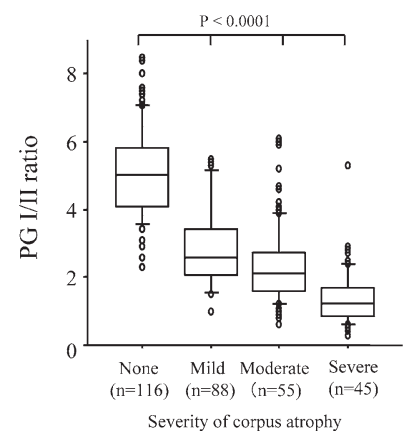

$\mathrm{C}$

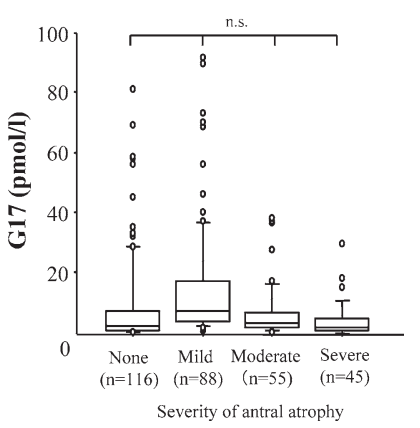

Fig. 1. Serum biomarker profile according to the severity of antral or corpus atrophy. Box plot shows the comparison between the severity of corpus atrophy and serum PG I (A) and PG I/II ratio (B), and between the severity of antral atrophy and serum G17 (C). The ends of the boxes define the 25th and 75th percentiles, with the horizontal line indicating the median value in the boxes and error bars defining the 10th and 90th percentiles. The severity of mucosal atrophy in the antrum and corpus was determined by the mean atrophy score of two biopsy samples. None, no atrophy (mean atrophy score 0-0.5); Mild, mild atrophy (mean atrophy score 1-1.5); Moderate, moderate atrophy (mean atrophy score 2-2.5); Severe, severe atrophy (mean atrophy score 3); PG, pepsinogen; G17, gastrin17; n.s., not significant. The statistical significance was determined by Spearman's rank correlation test.
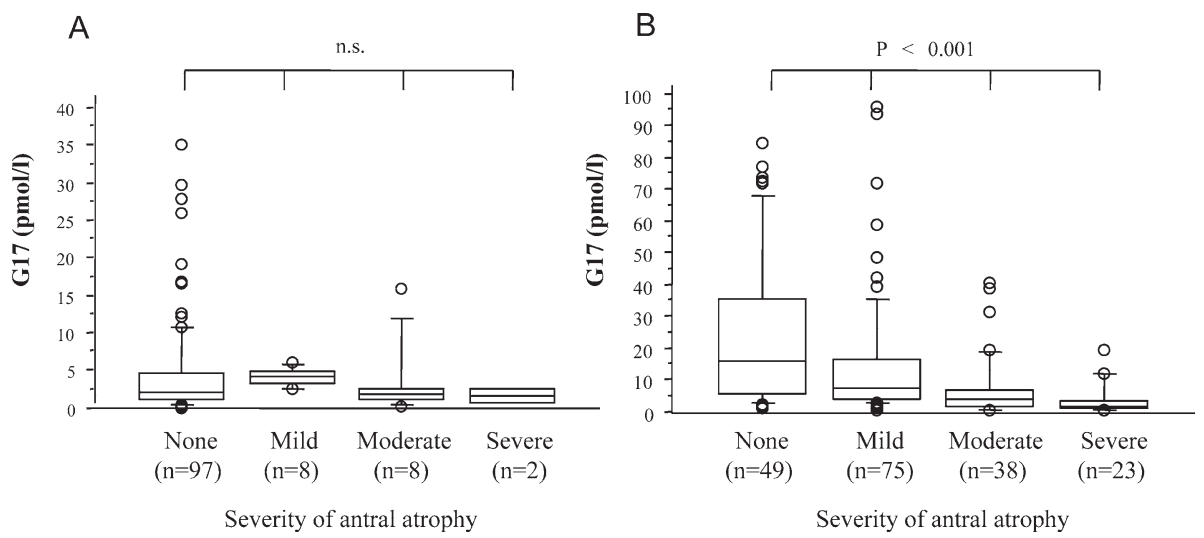

Fig. 2. The relationship between serum G17 level and the severity of antral atrophy according to the presence or absence of corpus atrophy. Box plot shows the comparison between serum G17 level and the severity of antral atrophy in the absence of corpus atrophy (A) and in the presence of corpus atrophy (B). The ends of the boxes define the 25th and 75th percentiles, with the horizontal line indicating the median value in the boxes and error bars defining the 10th and 90th percentiles. The severity of mucosal atrophy in the antrum was determined by the mean atrophy score of two biopsy samples. None, no atrophy (mean atrophy score 0-0.5); Mild, mild atrophy (mean atrophy score 1-1.5); Moderate, moderate atrophy (mean atrophy score 2-2.5); Severe, severe atrophy (mean atrophy score 3); PG, pepsinogen; G17, gastrin17; n.s., not significant. The statistical significance was determined by Spearman's rank correlation test. 
A

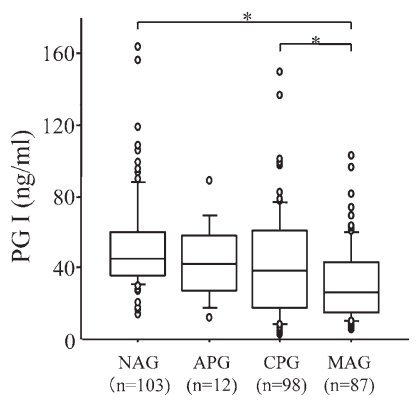

B

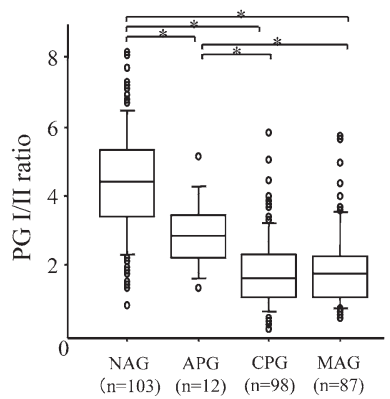

$\mathrm{C}$

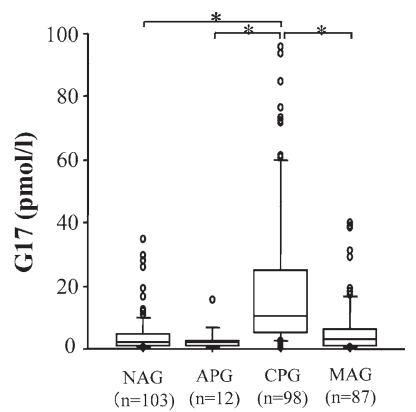

Fig. 3. Serum biomarker profile in the 4 histologically classified group of atrophic gastritis. Box plot shows the level of serum PG I (A), PGI/II ratio (B) and serum G17 (C) in the 4 subgroups of atrophic gastritis. The ends of the boxes define the 25th and 75th percentiles, with the horizontal line indicating the median value in the boxes and error bars defining the 10th and 90th percentiles. NAG, non-atrophic gastritis; APG, antrum-predominant atrophic gastritis; CPG, corpus-predominant atrophic gastritis; MAG, multifocal atrophic gastritis PG, pepsinogen; $\mathrm{G} 17$, gastrin 17; * $p<0.05$, Tukey-Kramer test

Table 3. Gastric cancer risk estimated by the histological and topographic assessment of gastric atrophy.

\begin{tabular}{llcc}
\hline & \multicolumn{1}{c}{ subgroup } & unadjusted OR $(95 \% \mathrm{CI})$ & adjusted OR $(95 \% \mathrm{CI})$ \\
\hline age (years) & continuous variables & $1.08(1.06-1.11)$ & $1.05(1.02-1.08)$ \\
gender & female & 1.0 & 1.0 \\
& male & $2.35(1.43-3.87)$ & $2.47(1.35-4.52)$ \\
H. pylori infection & negative & 1.0 & 1.0 \\
& positive & $2.88(1.66-4.99)$ & $0.729(0.31-1.70)$ \\
histological pattern of AG & NAG* & 1.0 & 1.0 \\
& APG & $13.71(3.49-53.83)$ & $13.73(3.06-61.53)$ \\
& CPG & $11.64(4.97-27.63)$ & $8.61(3.08-24.04)$ \\
& MAG & $38.16(15.46-94.18)$ & $25.06(8.69-72.27)$
\end{tabular}

NAG, histological non-atrophic gastritis; APG, histological antrum-predominant atrophic gastritis; CPG, histological corpus-predominant atrophic gastritis; MAG, histological multiple atrophic gastritis; CI, confidence interval; OR, odds ratio.

Table 4. Gastric cancer risk estimated by the serological assessment of gastric atrophy.

\begin{tabular}{llcc}
\hline & \multicolumn{1}{c}{ subgroup } & unadjusted OR $(95 \%$ CI) & adjusted OR (95\% CI) \\
\hline age (years) & continuous variables & $1.08(1.06-1.11)$ & $1.08(1.05-1.11)$ \\
gender & female & 1.0 & 1.0 \\
& male & $2.35(1.43-3.87)$ & $2.51(1.39-4.54)$ \\
H. pylori infection & negative & 1.0 & 1.0 \\
& positive & $2.88(1.66-4.99)$ & $0.98(0.465-2.07)$ \\
serological pattern of AG & s-NAG or s-APG & 1.0 & 1.0 \\
& s-CPG & $4.94(2.90-8.41)$ & $3.72(3.08-24.04)$ \\
& s-MAG & $30.56(6.59-141.74)$ & $26.90(5.37-134.83)$ \\
\hline
\end{tabular}

s-NAG, serologically defined non-atrophic gastritis;s-APG, serologically defined antrum-predominant atrophic gastritis; s-CPG, serologically defined corpus-predominant atrophic gastritis; s-MAG, serologically defined multifocal atrophic gastritis; PG, pepsinogen test; G17, gastrin-17. CI, confidence interval; OR, odds ratio.

gastric atrophy was significantly higher in the GC group than in the non-GC group in all 4 biopsy sites of the antrum and corpus.
Histological topographic pattern of gastric atrophy and gastric cancer risk

Most patients of the GC group were assigned to $\mathrm{CPG}$ (36.9\%) or MAG (52.5\%). The MAG pattern was significantly more prevalent and the NAG pattern was signifi- 
Table 5. Comparison of the diagnostic performance for detection of gastric cancer by different PG criteria and the combined PG/G17 criteria in this study population.

\begin{tabular}{lccc}
\hline & sensitivity & specificity & positive likelihood ratio \\
\hline Conventional PG & $77.9 \%$ & $61.8 \%$ & 2.0 \\
Strict PG & $41.3 \%$ & $90.4 \%$ & 4.2 \\
Combined PG/G17 & $12.3 \%$ & $98.9 \%$ & 11.2 \\
\hline
\end{tabular}

PG, pepsinogen test; G17, gastrin 17.

Conventional PG, PG I $\leq 70 \mathrm{ng} / \mathrm{ml}$ and $\mathrm{PG} \mathrm{I/II} \mathrm{ratio} \leq 3$.

Strict $\mathrm{PG}, \mathrm{PG} \mathrm{I} \leq 30 \mathrm{ng} / \mathrm{ml}$ and $\mathrm{PG} \mathrm{I} / \mathrm{II}$ ratio $\leq 2$.

Combined PG/G17, PG I $\leq 70 \mathrm{ng} / \mathrm{ml}$ and PG $\mathrm{I} / \mathrm{II}$ ratio $\leq 3$ and serum $\mathrm{G} 17 \leq 1 \mathrm{pmol} / \mathrm{l}$.

cantly less prevalent in the GC group than in the non-GC group after adjusting for age (Table 2). CPG was similarly prevalent at about $30-40 \%$ in both groups. APG was uncommon in both groups with a low prevalence of approximately $3-4 \%$.

As shown in Table 3, age and male gender was determined to be significant risks factor for gastric cancer both by univariate and multivariate analysis. The positivity of H.pylori infection was found to be a significant cancer risk by univariate analysis (unadjusted odds ratio 2.88), but not by multivariate analysis (adjusted odds ratio 0.73 ). When using the NAG group as a reference, the adjusted odds ratio for gastric cancer in each histologically classified group of atrophic gastritis was 13.7 for APG, 8.6 for CPG and 25.1 for MAG. Thus, MAG had the histological topographic pattern of gastric atrophy with the highest risk for gastric cancer after controlling for age, gender and $H$. pylori infection.

The relationship between serum biomarkers and the severity of antral or corpus atrophy

To evaluate the validity of serum biomarker as an indicator for gastric atrophy, we analyzed the relationship between serum biomarkers and the severity of antral or corpus atrophy in all subjects together. The serum PG, especially PG I/II ratio, significantly and stepwisely decreased with the increasing grade of corpus atrophy (PG I - none corpus atrophy, $49.5 \pm 22.6 \mathrm{ng} / \mathrm{ml}$; mild, $55.3 \pm 31.5 \mathrm{ng} / \mathrm{ml}$; moderate, $45.7 \pm 25.1 \mathrm{ng} / \mathrm{ml}$; severe, $22.6 \pm 22.6 \mathrm{ng} / \mathrm{ml}$, PG I/II - non corpus atrophy, $5.1 \pm 1.4$; mild, $2.9 \pm 1.2$; moderate, $2.6 \pm 1.1$; severe, $1.4 \pm 0.8$ ) (Fig. 1A, B). On the other hand, there was no significant correlation between the serum G17 level and the severity of antral atrophy (G17 none antral atrophy, $9.5 \pm 16.7 \mathrm{pmol} / \mathrm{l}$; mild, $16.3 \pm 20.3$ $\mathrm{pmol} / \mathrm{l}$; moderate $7.0 \pm 9.5 \mathrm{pmol} / \mathrm{l}$; severe, $4.6 \pm 6.4 \mathrm{pmol} / \mathrm{l}$ ) (Fig. 1C). When examined the relationship between serum G17 level and the severity of antral atrophy separately according to the presence or absence of corpus atrophy, serum G17 significantly decreased with the severity of antral atrophy in the presence of corpus atrophy whereas no correlation between them was found in the absence of it (Fig. 2A, B). Thus, these observations suggested that serum PG could be a reasonable serological indicator for corpus atrophy, while serum G17 could be a possible marker of antral atrophy in the coexistence of corpus atrophy.

Serum biomarker profile according to the histological topography of gastric atrophy

Next, we examined serum biomarker profiles in the 4 histologically classified subgroups of atrophic gastritis (NAG, APG, CPG and MAG) in all subjects together. Serum PG I in the MAG was lower compared with that in the NAG and CPG with statistical significance, but there was a large overlap between the CPG and MAG group (NAG, $52.1 \pm 25.5 \mathrm{ng} / \mathrm{ml} ;$ APG, $43.6 \pm 21.3 \mathrm{ng} / \mathrm{ml} ; \mathrm{CPG}$, $43.1 \pm 29.9 \mathrm{ng} / \mathrm{ml}$; MAG, $31.8 \pm 20.9 \mathrm{ng} / \mathrm{ml}$ ) (Fig. $3 \mathrm{~A}$ ). The PG I/II ratio in the NAG group was significantly higher compared with the other 3 subgroups and the ratio in the APG was also significantly higher than that in the CPG or MAG group, but there was no difference between CPG and MAG (NAG, $4.6 \pm 1.6$; APG, $3.1 \pm 1.0 ; \mathrm{CPG}, 2.0 \pm 1.1$; MAG, $2.1 \pm 1.2$ ) (Fig. 3B). On the other hand, serum G17 in the CPG was exclusively elevated among the 4 subgroups of $\mathrm{AG}$, resulting in only a little overlap between CPG and the other subgroups (NAG, $4.4 \pm 6.3 \mathrm{pmol} / \mathrm{l}$; APG, $2.9 \pm 4.1 \mathrm{pmol} / \mathrm{l} ; \mathrm{CPG}, 20.8 \pm 23.0 \mathrm{pmol} / \mathrm{l} ; \mathrm{MAG}, 6.3 \pm 8.7$ pmol/l) (Fig. 3C). These results suggest that a combination of low PG (especially low PG I/II ratio) and low G17 may be useful for the serological determination of the MAG pattern of AG, although measurement of either alone was inadequate for evaluation.

Serological topographic classification of gastric atrophy and risk assessment for gastric cancer

As established previously (Dinis-Ribeiro et al. 2004), the subjects with PG I $\leq 70 \mathrm{ng} / \mathrm{ml}$ and PG I/II ratio $\leq 3$ (positive PG test) were defined to have serological corpus atrophy, while those with PG I > $70 \mathrm{ng} / \mathrm{ml}$ and/or PG I/II ratio $>3$ (negative PG test) were serologically diagnosed to be free of corpus atrophy. On the other hand, based on a reference range of serum fasting G17 in the manufacturer's instructions $(1-10 \mathrm{pmol} / \mathrm{l})$, the subjects with $\mathrm{G} 17 \leq 1 \mathrm{pmol} / 1$ were defined to have serological antral atrophy (Iijima et al. 2009), and all subjects were serologically divided into the following 4 subgroups: negative PG test and G17 > $1 \mathrm{pmol} /$ 1, serological NAG; nagative PG test and G17 $\leq 1 \mathrm{pmol} / \mathrm{l}$, serological APG; positive PG test and G17 > 1 pmol/1, serological CPG; positive PG test and G17 $\leq 1 \mathrm{pmol} / 1$, serologi- 
cal MAG.

Although $\mathrm{G} 17 \leq 1 \mathrm{pmol} / \mathrm{l}$ was defined as a barometer for gastric antral atrophy, a decrease of serumG17 suggests not only loss of gastrin secreting $G$ cells but also high intragastric acidity that inhibits the release of G17 from antral G cells (Sipponen et al. 2002b, 2005; Väänänen et al. 2003). Thus, as depicted even in our results (see Fig. 2A and 2B, Fig. 3C), due to the limited ability of serum G17 to discriminate the antral atrophy in the absence of corpus atrophy (Sipponen et al. 1990; Storskrubb et al. 2008), we grouped serological NAG and serological APG together, and used them as a reference. Then, the odds ratio for gastric cancer in each subgroup was calculated by univariate and multivariate analysis (Table 4). Using the serological NAG and APG group as a reference, the adjusted odds ratio for gastric cancer in the serological $\mathrm{CPG}$ and serological MAG was 3.7 and 26.9, respectively. Thus, as well the histological-classified MAG, the serologically classified MAG was found to have a markedly and significantly high-risk for gastric cancer after controlling for age, gender and $H$. pylori infection.

\section{Comparison of risk assessment and diagnostic performance} for gastric cancer by different serological tests

The serological risk assessment of gastric cancer using "the low PG and low G17 combined criteria (PG I $\leq$ $70 \mathrm{ng} / \mathrm{ml}$ and PG I/II ratio $\leq 3$ and G17 $\leq 1 \mathrm{pmol} / \mathrm{ll}$ )" was compared with that using "the conventional PG criteria (PG $\mathrm{I} \leq 70 \mathrm{ng} / \mathrm{ml}$ and PG I/II ratio $\leq 3$ )" and "the strict PG criteria $(\mathrm{PG} \leq 30 \mathrm{ng} / \mathrm{ml}$ and $\mathrm{PG} \mathrm{I} / \mathrm{II}$ ratio $\leq 2)$ ". Using the subjects not fulfilling the respective criteria as a reference, multivariate analysis showed that the odds ratio for gastric cancer in the subjects with positive results of the conventional PG, the strict PG and the low PG and low G17 combined criteria was 4.5 (95\% C.I., 2.4-8.7, $p<0.0001)$, 3.8 (95\% C.I., 2.0-7.4, $p<0.0001)$ and 11.8 (95\% C.I., 2.5$55.1, p=0.0018$ ), respectively (Table not shown).

The sensitivity, specificity and positive likelihood ratio were calculated using the above 3 different criteria in order to test the diagnostic performance of gastric cancer. As shown in table 5, the sensitivity decreased from $77.9 \%$ in the conventional PG criteria to $41.3 \%$ in the strict PG criteria, and further fell to $12.3 \%$ in the low PG and low G17 combined criteria. In contrast, the specificity increased in steps from $61.8 \%$ in the conventional PG criteria to $98.9 \%$ in the low PG and low G17 combined criteria. The positive likelihood ratio calculated by the low PG and low G17 combined criteria was 11.2 , being the highest among these 3 criteria (conventional PG, 2.0; strict PG, 4.2).

\section{Discussion}

We first confirmed in this study by histological assessment using multiple gastric biopsies that the presence of antral atrophy in addition to corpus atrophy, as referred to as the MAG, was associated with a markedly increased risk for gastric cancer, although a vast majority of patients with gastric cancer have corpus atrophic gastritis. Next, for the first time, we found that MAG could be serologically identified by the combination of low PG and low G17, and that the serologically defined MAG showed a markedly high risk for gastric cancer as consistent with estimation by the histological analysis. Therefore, in the mass screening of early gastric cancer, it is important how to efficiently determine the MAG pattern atrophy.

Early studies among Japanese subjects, the population known to have a high prevalence of $H$. pylori infection and its-induced atrophic gastritis (Asaka et al. 1992), have shown that gastric atrophy develops initially in the antrum and sequentially spreads to the corpus with age (Kimura and Takemoto 1969; Kimura 1972). Thus, it has been widely recognized in Japan that corpus atrophy usually entails antral atrophy. Since corpus atrophy is exclusively crucial to the risk of gastric cancer, little attention has been paid to antral atrophy. Our present study clarified the intrinsic significance of antral atrophy in assessing the risk of gastric cancer in Japanese patients, being compatible with previous histological reports from Western countries (Sipponen and Stolte 1997; Rugge et al. 2007). In addition, regarding the topographic pattern of gastric atrophy, this study showed that more than half of individuals whose corpus mucosa was eroded by atrophic change were free of antral atrophy (98 individuals with CPG in 185 individuals with CPG or MAG), and that such subjects (CPG) constituted about $30-40 \%$ in both the adjusted non-GC group and the GC group. This finding might provide a conflict with the traditional recognition on the topographic distribution of atrophic gastritis in Japanese subjects (Kimura and Takemoto 1969; Kimura 1972; Satoh et al. 1998) as mentioned above. It has been reported that there has been a significant increase in gastric acid secretion associated with dramatic westernization of diet in Japanese subjects over the past decades, irrespective of $H$. pylori infection (Kinoshita et al. 1997). There is also a relatively sharp reduction of $H$. pylori prevalence in Japan (Fujisawa et al. 1999). Those observations may alter the gastric milieu, possibly leading to changes in the prevalence or pattern of chronic gastritis including autoimmune gastritis.

As have demonstrated in many previous reports (Dinis-Ribeiro et al. 2004), our study found that serum PG could be a good serological indicator of corpus atrophy. However, as illustrated in Figure1C, there was no significant correlation between serum G17 and increasing grade of antral atrophy, indicating that a low level of serum G17 is not directly linked to antral atrophy. This observation can be explained by serum profile of G17, which decreases not only by a loss of antral $\mathrm{G}$ cells but also by a feed-back inhibition of G17 release from antral G cells driven by high intragastric acidity (Sipponen et al. 1990, 2005). For instance, in this study, serum G17 less than $1 \mathrm{pmol} / 1$ was observed even in 20 subjects of the NAG group, which is free from antral atrophy. This could be a cause of serological misinterpretation of antral atrophy. However, as 
depicted in Fig. 2B, a significant inverse correlation was shown between serum G17 and the severity of antral atrophy in the coexistence of corpus atrophy. Consequently, coexisting corpus atrophy allows us to rule out the possibility of feed-back inhibition of G17 release by high intragastric acidity, making use of a low level of serum G17 as a more reliable biomarker to predict the presence of antral atrophy (Sipponen et al. 1990, 2002b; Germaná et al. 2005). Indeed, in this study, serum G17 of less than $1 \mathrm{pmol} / 1$ was found only in one of $98 \mathrm{CPG}$ patients, who had corpus atrophy but lacked antral atrophy. To serologically and reliably evaluate the topographic pattern of AG, a combination of serum PG and G17 would be needed.

Although accumulating evidence suggests the usefulness of serum PG for serological risk assessment for gastric cancer (Kitahara et al. 1999; Varis et al. 2000; Miki et al. 2003; Watabe et al. 2005; Oishi et al. 2006; Yanaoka et al. 2008), there are only a few reports on serum G17. In the previous reports, it was described that an increased level of serum G17 was useful for cancer screening by improving the serological detection of corpus atrophy (Shiotani et al. 2005; Rollan et al. 2006; Cao et al. 2007). In contrast, our study indicated that a decreased level of serum G17, combined with a low level of PG, could be useful for the risk assessment of gastric cancer through serologically determining extensive atrophic gastritis, assigned to the MAG in this study. The low sensitivity (12.3\%) of these criteria for the detection of gastric cancer, however, would preclude its general usage such as community-based mass screening. Nonetheless, the high specificity $(98.9 \%)$ and positive likelihood ratio (11.2) of the combined criteria would suggest a potential advantage under a specific situation such as stratification and management of super high-risk individuals for gastric cancer (Stengel et al. 2003). For instance, we could recommend individuals with the positive results for our "low PG and low G17 combined criteria" to undergo annual endoscopic examination rather than mass screening with Xray due to its exclusive high specificity for gastric cancer.

The reasons why the risk for gastric cancer increased dramatically in coexisting antral and corpus atrophy (the MAG group) compared with corpus atrophy alone (the CPG group) are unclear. Hypochrolhydria, which is a well known high-risk factor for gastric cancer (Siurala et al. 1966; Svendsen et al. 1986; Correa et al.1990), accompanied by corpus atrophy, should be at similar levels in CPG and MAG (Derakhshan et al. 2006). Simply, the larger area undergoing atrophic changes including intestinal metaplasia in MAG may result in a higher risk of developing cancer (Cassaro et al. 2000; Faraji and Frank 2002). Additionally, the etiology per se may also be different between the two types of gastritis. That is, H. pylori infection and other triggering factors such as anti-parietal cell antibody may contribute differently to the etiology resulting in distinctive carcinogenic potentials in two types of gastritis (Sugiu et al. 2006; Taguchi et al. 2006).

The strength of this study is that only patients with early gastric cancer, in whom the tumor size was small and cancer invasion was confined to mucosa or submucosa, were enrolled. In cases with advanced gastric cancer, expansion of tumor damages the stomach functionally and morphologically, possibly impairing appropriate interpretation of gastric serum biomarkers. Since most of early gastric cancer is at a curable stage, a serological screening with the appropriate biomarkers could contribute to decreasing the mortality of gastric cancer. On the other hand, a potential limitation is the bias in choosing the non-GC group from outpatients who visited our university hospital, which does not reflect the general population. Although H. pylori prevalence and serum PG value in the non-GC group of this study were similar to those of the asymptomatic Japanese volunteers in a previous study (Asaka et al. 1992), a further study with appropriate controls reflecting the general population is required. Another potential limitation is that this study was enrolled mainly in intestinal type gastric cancers. Since there is only a weak link between atrophic gastritis and the development of diffuse-type gastric cancer (Correa 1992; Palli et al. 2007), further studies including patients with diffuse-type gastric cancers are needed.

In conclusion, this study has demonstrated that not only corpus atrophy but also antral atrophy is strongly associated with an increased risk for gastric cancer in Japanese subjects. Furthermore, the measurement of serum G17 in combination with serum PG would be beneficial in assessing the topographical pattern of AG and its related gastric cancer risk as a non-invasive method.

\section{Acknowledgment}

Special thanks to our laboratory personnel including Heidi Tsang and Ritva Kara for measuring the GastroPanel tests and, of course, many thanks to Dr. Aino Telaranta-Keerie for organizing the testing in the laboratory. Thanks also to Biohit Japan for organizing the shipment of the samples.

\section{References}

Asaka, M., Kimura, T., Kudo, M., Takeda, H., Mitani, S., Miyazaki, T., Miki, K. \& Graham, D.Y. (1992) Relationship of Helicobacter pylori to serum pepsinogens in an asymptomatic Japanese population. Gastroenterology, 102, 760-766.

Borch, K., Axelsson, C.K., Halgreen, H., Damkjaer, N.M.D., Ledin, T. \& Szesci, P.B. (1989) The ratio of pepsinogen A to pepsinogen C: a sensitive test for atrophic gastritis. Scand. J. Gastroenterol., 24, 870-876.

Broutet, N., Plebani, M., Sakarovitch, C., Sipponen, P. \& Mégraud, F.; the Eurohepygast Study Group. (2003) Pepsinogen A, pepsinogen $\mathrm{C}$, and gastrin as markers of atrophic chronic gastritis in European dyspeptics. Br. J. Cancer, 88, 12391247.

Cao, Q., Ran, Z.H. \& Xiao, S.D. (2007) Screening of atrophic gastritis and gastric cancer by serum pepsinogen, gastrin-17 and Helicobacter pylori immunoglobulin G antibodies. J. Dig. Dis., 8, 15-22.

Cassaro, M., Rugge, M., Gutierrez, O., Leandro, G., Graham, D.Y. \& Genta, R.M. (2000) Topographic patterns of intestinal metaplasia and gastric cancer. Am. J. Gastroenterol., 95, 1431-1438.

Correa, P. (1992) Human gastric carcinogenesis: a multistep and 
multifactorial process- First American Cancer Society Award Lecture on Cancer Epidemiology and Prevention. Cancer Res., 52, 6735-6740.

Correa, P., Haenszel, W., Cuello, C., Zavala, D., Fontham, E., Zarama, G., Tannenbaum, S., Collazos, T. \& Ruiz, B. (1990) Gastric precancerous process in a high risk population: cohort follow-up. Cancer Res., 50, 4737-4740.

Derakhshan, M.H., El-Omar, E., Oien, K., Gillen, D., Fyfe, V., Crabtree, J.E. \& McColl, K.E. (2006) Gastric histology, serological markers and age as predictors of gastric acid secretion in patients infected with Helicobacter pylori. J. Clin. Pathol., 59, 1293-1299.

di Mario, F. \& Cavallaro, L.G. (2008) Non-invasive tests in gastric disease. Dig. Liver Dis., 40, 523-530.

Dinis-Ribeiro, M., Yamaki, G., Miki, K., Costa-Pereira, A., Matsukawa, M. \& Kurihara, M. (2004) Meta-analysis on the validity of pepsinogen test for gastric carcinoma, dysplasia or chronic atrophic gastritis screening. J. Med. Screen., 11, 141147.

Dixon, M.F., Genta, R.M., Yardley, J.H. \& Correa, P. (1996) Classification and grading of gastritis. The updated Sydney system. International Workshop on the Histopathology of Gastritis, Houston 1994. Am. J. Surg. Pathol., 20, 1161-1181.

Faraji, E.I. \& Frank, B.B. (2002) Multifocal atrophic gastritis and gastric carcinoma. Gastroenterol. Clin. North. Am., 31, 499516.

Fujisawa, T., Kumagai, T., Akamatsu, T., Kiyosawa, K. \& Matsunaga, Y. (1999) Changes in seroepidemiological pattern of Helicobacter pylori and hepatitis A virus over the last 20 years in Japan. Am. J. Gastroenrerol., 94, 2094-2099.

Germaná, B., Mario, F., Cavallaro, L.G., Moussa, A.M., Lecis, P., Liatoupolou, S., Comparato, G., Carloni, C., Bertiato, G., Battiestel, M., Papa, N., Aragona, G., Cavestro, G.M., Iori, V., Merli, R., Bertolini, S., Caruana, P. \& Franzé, A. (2005) Clinical usefulness of serum pepsinogens I and II, gastrin-17 and anti-Helicobacter pylori antibodies in the management of dyspeptic patients in primary care. Dig. Liver Dis., 37, 501508 .

Iijima, K., Abe, Y., Kikuchi, R., Koike, T., Ohara, S., Sipponen, P. \& Shimosegawa, T. (2009) Serum biomarker tests are useful in delineating between patients with gastric atrophy and normal, healthy stomach. World J. Gastroenterol., 15, 853859.

Kimura, K. \& Takemoto, T. (1969) An endoscopic recognition of the atrophic border and its significance in chronic gastritis. Endoscopy, 3, 87-97.

Kimura, K. (1972) Chronological transition of the fundic-pyloric border determined by stepwise biopsy of the lesser and greater curvatures of the stomach. Gastroenterology, 63, 584-592.

Kinoshita, Y., Kawanami, C., Kishi, K., Nakata, H., Seino, Y. \& Chiba, T. (1997) Helicobacter pylori independent chronological change in gastric acid secretion in the Japanese. Gut, 41, 452-458.

Kitahara, F., Kobayashi, K., Sato, T., Kojima, Y., Araki, T. \& Fujino, M.A. (1999) Accuracy of screening for gastric cancer using serum pepsinogen concentrations. Gut, 44, 693-697.

Miki, K., Ichinose, M., Shimizu, A., Huang, S.C., Oka, H., Furihata, C., Matsushima, T. \& Takahashi, K. (1987) Serum pepsinogens as a screening test of extensive chronic gastritis. Gastroenterol. Jpn., 22, 133-141.

Miki, K., Morita, M., Sasajima, M., Hoshina, R., Kanda, E. \& Urita, Y. (2003) Usefulness of gastric cancer screening using the serum pepsinogen test method. Am. J. Gastroenterol., 98, 735-739.

Oishi, Y., Kiyohara, Y., Kubo, M., Tanaka, K., Tanizaki, Y., Ninomiya, T., Doi, Y., Shikata, K., Yonemoto, K., Shirota, T., Matsumoto, T. \& Iida, M. (2006) The serum pepsinogen test as a predictor of gastric cancer: the Hisayama study. Am. J. Epidemiol., 163, 629-637.
Palli, D., Masala, G., Del Giudice, G., Plebani, M., Basso, D., Berti, D., Numans, M.E., Ceroti, M., Peeters, P.H., Bueno, H.B., Buchner, F.L., Clavel, C.F., Boutron-Ruault, M.C., Krogh, V., Saieva, C., Vineis, P., Panico, S., Tumino, R., Nyrén, O., Simán, H., Berglund, G., Hallmans, G., Sanchez, M.J., Larrãnaga, N., Barricarte, A., Navarro, C., Quiros, J.R., Key, T., Allen, N., Bingham, S., Khaw, K.T., Boeing, H., Weikert, C., Linseisen, J., Nagel, G., Overvad, K., Thomsen, R.W., Tjonneland, A., Olsen, A., Trichoupoulou, A., Trichopoulos, D., Arvaniti, A., Pera, G., Kaaks, R., Jenab, M., Ferrari, P., Nesi, G., Carneiro, F., Riboli, E. \& Gonzalez, C.A. (2007) CagA + Helicobacter pylori infection and gastric cancer risk in the EPIC-EURGAST study. Int. J. Cancer, 120, 859-867.

Rollan, A., Ferreccio, C., Gederlini, A., Serrano, C., Torres, J. \& Harris, P. (2006) Non-invasive diagnosis of gastric mucosal atrophy in an asymptomatic population with high prevalence of gastric cancer. World J. Gastroenterol., 12, 7172-7178.

Rugge, M., Meggio, A., Pennelli, G., Piscioli, F., Giacomelli, L., De Pretis, G. \& Graham, D.Y. (2007) Gastritis staging in clinical practice: the OLGA staging system. Gut, 56, 631-636.

Ruiz, B., Garay, J., Johnosn, W., Li, D., Rugge, M., Dixon, M.F., Fiocca, R., Genta, R.M., Hattori, T., Lechago, J., Price, A.B., Sipponen, P., Solcia, E., Watanabe, H. \& Correa, P. (2001) Morphometric assessment of gastric antral atrophy: comparison with visual evaluation. Histopathology, 39, 235-242.

Samloff, I.M. (1971) Cellular localization of group I pepsinogens in human gastric mucosa by immunofluorescence. Gastroenterology, 61, 185-188.

Samloff, I.M. \& Liebman, W.M. (1973) Cellular localization of the group II pepsinogens in human stomach and duodenum by immunofluorescence. Gastroenterology, 65, 36-42.

Satoh, K., Kimura, K., Taniguchi, Y., Kihira, K., Takimoto, T., Saifuku, K., Kawata, H., Tokumaru, K., Kojima, T., Seki, M., Ido, K. \& Fujioka, T. (1998) Biopsy sites suitable for the diagnosis of Helicobacter pylori infection and the assessment of the extent of atrophic gastritis. Am. J. Gastroenterol., 93, 569-573.

Shiotani, A., Iishi, H., Uedo, N., Kumamoto, M., Nakae, Y., Ishiguro, S., Tatsuta, M. \& Graham, D.Y. (2005) Histologic and serum risk markers for noncardia early gastric cancer. Int. J. Cancer, 115, 463-469.

Sipponen, P., Härkönen, M., Alanko, A. \& Suovaniemi, O. (2002a) Diagnosis of atrophic gastritis from a serum sample. Clin. Lab., 48, 505-515.

Sipponen, P., Ranta, P., Helske, T., Kääriäinen, I., Mäki, T., Linnala, A., Suovaniemi, O., Alanko, A. \& Härkönen, M. (2002b) Serum levels of amidated gastrin-17 and pepsinogen I in atrophic gastritis: an observational case control study. Scand. J. Gastroenterol., 37, 785-791.

Sipponen, P. \& Stolte, M. (1997) Clinical impact of routine biopsies of the gastric antrum and body. Endoscopy, 29, 671-678.

Sipponen, P., Valle, J., Varis, K., Kekki, M., Ihamäki, T. \& Siurala, M. (1990) Fasting levels of serum gastrin in different functional and morphologic states of the antrofundal mucosa. An analysis of 860 subjects. Scand. J. Gastroenterol., 25, 513-519.

Sipponen, P., Vauhkonen, M., Helske, T., Kaariainen, I. \& Harkonen, M. (2005) Low circulating levels of gastrin-17 in patients with Barrett's esophagus. World J. Gastroenterol., 11, 5988-5992.

Siurala, M., Varis, K. \& Wiljasalo, M. (1966) Studies of patients with atrophic gastritis: a 10-15-year follow-up. Scand. J. Gastroenterol., 1, 40-48.

Staibano, S., Rocco, A., Mezza, E., De Rosa, G., Budillon, G. \& Nardone, G. (2002) Diagnosis of chronic atrophic gastritis by morphometric image analysis. A new method to overcome the confounding effect of the inflammatory infiltrate. J. Pathol., 198, 47-54. 
Stengel, D., Bauwens, K., Sehouli, J., Ekkernkamp, A. \& Porzsolt, F. (2003) A likelihood ratio approach to meta-analysis of diagnostic studies. J. Med. Screen., 10, 47-51.

Stockbrugger, R., Larsson, L.I., Lundqvist, G. \& Angervall, L. (1977) Antral gastrin cells and serum gastrin in achlorhydria. Scand. J. Gastroenterol., 12, 209-213.

Storskrubb, T., Aro, P., Ronkainen, J., Sipponen, P., Nyhlin, H., Talley, N.J., Engstrand, L., Stolte, M., Vieth, M., Walker, M. \& Agreus, L. (2008) Serum biomarkers provide an accurate method for diagnosis of atrophic gastritis in a general population: the Kalixanda study. Scand. J. Gastroenterol., 43, 14481455.

Sugiu, K., Kamada, T., Ito, M., Kaya, S., Tanaka, A., Kusunoki, H., Hata, J. \& Haruma, K. (2006) Anti-parietal cell antibody and serum pepsinogen assessment in screening for gastric carcinoma. Dig. Liver Dis., 38, 303-307.

Svendsen, J.H., Dahl, C., Sevendsen, L.B. \& Christiansen, P.M. (1986) Gastric cancer risk in achlorhydric patients. A longterm follow-up study. Scand. J. Gastroenterol., 21, 16-20.

Taguchi, A., Ohmiya, N., Itoh, A., Hirooka, Y., Niwa, Y., Mori, N. \& Goto, H. (2006) Severity of atrophic gastritis related to antiparietal cell antibody and gastric carcinogenesis, including p53 mutations. J. Gastroenterol. Hepatol., 21, 545-551.

Uemura, N., Okamoto, S., Yamamoto, S., Matsumura, N., Yamaguchi, S., Yamakido, M., Taniyama, K., Sasaki, N. \& Schlemper, R.J. (2001) Helicobacter pylori infection and the development of gastric cancer. N. Engl. J. Med., 345,
784-789.

Varis, K., Sipponen, P., Laxén, F., Samloff, I.M., Huttunen, J.K., Taylor, P.R., Heinonen, O.P., Albanes, D., Sande, N., Virtamo, J. \& Härkönen, M. (2000) Implications of serum pepsinogen I in early endoscopic diagnosis of gastric cancer and dysplasia. Helsinki Gastritis Study Group. Scand. J. Gastroenterol., 35, 950-956.

Väänänen, H., Vauhkonen, M., Helske, T., Kääriäinen, I., Rasmussen, M., Tunturi, H.H., Koskenpato, J., Sotka, M., Turunen, M., Sandström, R., Ristikankare, M., Jussila, A. \& Sipponen, P. (2003) Non-endoscopic diagnosis of atrophic gastritis with a blood test. Correlation between gastric histology and serum levels of gastrin-17 and pepsinogen I: a multicentre study. Eur. J. Gastroenterol. Hepatol., 15, 885-891.

Watabe, H., Mitsushima, T., Yamaji, Y., Okamoto, M., Wada, R., Kokubo, T., Doi, H., Yoshida, H., Kawabe, T. \& Omata, M. (2005) Predicting the development of gastric cancer from combining Helicobacter pylori antibodies and serum pepsinogen status: a prospective endoscopic cohort study. Gut, 54, $764-768$.

Yanaoka, K., Oka, M., Mukoubayashi, C., Yoshimura, N., Enomoto, S., Iguchi, M., Magari, H., Utsunomiya, H., Tamai, H., Arii, K., Ohata, H., Fujishiro, M., Takeshita, T., Mohara, O. \& Ichinose, M. (2008) Cancer high-risk subjects identified by serum pepsinogen tests: outcomes after 10-year follow-up in asymptomatic middle-aged males. Cancer Epidemiol. Biomarkers Prev., 17, 838-845. 